\title{
Análisis estructural de tres columnas de Bambú y sus aplicaciones sostenibles en Arquitectura
}

\author{
Structural analysis of three bamboo columns and their sustainable applications in Architecture \\ Análise estrutural de três colunas de bambu e suas aplicações sustentáveis em Arquitetura
}

\author{
Fernando José da Silva. Ph.D. en Ingeniería de Estructuras. \\ fernandojsilva@ufmg.br \\ (iD) https://orcid.org/0000-0002-6031-6977 \\ Universidade Federal de Minas Gerais, Belo Horizonte, Brasil.
}

Recibido: Agosto 25 de 2018 Aceptado: Noviembre 15 de 2018 Publicado: Diciembre de 2018

\section{RESUMEN}

Este presente trabajo tiene como objetivo la presentación de resultados del análisis estructural experimental y numérico de tres diferentes columnas - denominadas híbrida, compuesta y haz- utilizando barras de bambú de la especie Phyllostachys pubescens. Se utilizaron, además de las barras de bambú, cables de acero, tornillos y cintas metálicas, de acuerdo con la configuración formal. Se permitió el perfeccionamiento de los procesos innovadores de construcción, con resultados y uso del Diagrama de Southwell, para conocimiento de la Carga de Euler. Se concluyó que el uso sostenible de estas columnas favorece la Biodiversidad, interactuando áreas del Diseño y de la Ingeniería.

Palabras clave: Columnas; bambú; diseño estructural; ensayo experimental.

\section{ABSTRACT}

The objective of this present work is to present the results of experimental and numerical structural analysis of three different columns - called hybrid, composite and beam-, using bamboo bars of the species Phyllostachys pubescens. In addition to the bamboo bars, steel cables, screws and metal belts were used, according to the formal configuration. The improvement of the innovative construction processes was allowed, with results and use of the Southwell Diagram, for knowledge of the Euler Load. It was concluded that the sustainable use of these columns favors Biodiversity, interacting areas of Design and Engineering.

Keywords: columns; bamboo; structural design; experimental trial.

\section{RESUMO}

O presente trabalho tem como objetivo a apresentação de resultados da análise estrutural experimental e numérica de três diferentes colunas, denominadas híbrida, composta e feixe utilizando barras de bambu da espécie Phyllostachys pubescens. Foram utilizados além das barras de bambu, cabos de aço, parafusos e cintas metálicas de acordo com a configuração formal. Permitiu-se aperfeiçoamento dos processos inovadores de construção, com resultados e uso do Diagrama de Southwell para conhecimento da Carga de Euler. Concluiu-se que o uso sustentável destas colunas favorece a Biodiversidade, interagindo as áreas do Design e da Engenharia.

Palavras-chave: Colunas; bambu; design estrutural; ensaio experimental. 


\section{Introdução}

O bambu, tubo natural da família da gramínea, cresce em toda região tropical e parte das regiões subtropicais do mundo, com mais de 1.200 espécies. No Brasil, a espécie Phyllostachys pubescens se apresenta como uma das mais resistentes e com eixo reto, encontrada em plantações nos estados do Rio de Janeiro e São Paulo, e podem atingir até 15 metros de comprimento com 10 centímetros de diâmetro médio. A aplicação de barras de bambus, como suporte de estruturas leves é uma escolha coerente, visto que se beneficia de um material cujas vantagens atuam na captação de carbono, produção de oxigênio, proteção da erosão do solo e assoreamento de rios e lagoas. Além das vantagens naturais, propõe-se o uso de material com desenvolvimento local tendo como base a gestão social como política correta na erradicação da pobreza, promovendo igualdade social no uso de recursos e possibilidades de crescimento sócio econômico das pessoas.

A sustentabilidade hoje é uma palavra de ordem, e o uso de recursos naturais, permite criação e desenvolvimento de diferentes sistemas de produção com design apropriado para cada tipo de utilização. Colunas construídas com barras de bambu podem ser utilizadas como velas de apoio em veleiros, além de poder ser utilizada como suporte em estruturas de tendas e elementos estruturais de construção civil em arquiteturas leves contemporâneas. As colunas aqui apresentadas neste trabalho, são fruto da pesquisa elaborada e testada no Laboratório de Sistema Estrutural - LASE e Laboratório de Análise Experimental de Estruturas - LAEES, respectivamente (UFMG), Belo Horizonte MG, Brasil. As colunas foram construídas com seis metros de comprimento, para se comparar seus resultados.

Foram três tipos desenvolvidos, denominadas de coluna híbrida, coluna composta e coluna de feixe de bambu. Ao longo do trabalho, serão apresentadas as características de cada tipo, seus resultados de testes de compressão e flexão, bem como a análise da Carga de Euler, apresentando limites de carga de utilização.

\section{Metodologia e processos}

Serão apresentados neste tópico, os métodos e processos de modelamento numérico das colunas utilizando software, os processos de construção física dos três tipos de colunas de bambu e os procedimentos durante os ensaios mecânicos destas colunas em laboratório.

\section{Modelamento Numérico através do software SAP 2000}

A modelagem das colunas foi realizada através do software via programa SAP 2000 (Computers and Structures, Inc, Berkeley, CA, 1995, v14). A opção por este software foi determinada pelo fato de ser, na ocasião, o único software disponível no LAEES, e limitação de recurso e tempo de execução da pesquisa. Sabe-se da existência de outros softwares de análise numérica, inclusive com mais recursos; porém, não foi objetivo do trabalho comparar resultados numéricos entre softwares, e sim a construção das colunas, e seus respectivos ensaios de compressão obtendo seu estado limite de utilização, inclusive validando os resultados com a análise numérica então existente. E a construção do protótipo foi realizada com base nos resultados da análise numérica estrutural realizada também pelo programa. Considerou-se para a modelagem, uma imperfeição inicial $e_{1}=L / 150$, onde $L$ é o comprimento da barra de bambu. Como aponta Moreira (1998), a excentricidade acidental deve ser considerada pelo menos igual ao dobro da excentricidade mínima das peças de madeira serrada, caso não haja condições de medição, que é de $L / 300$. Neste caso particular, tendo como comprimento da barra de bambu $L=6000 \mathrm{~mm}$, o valor da excentridicade foi de $20 \mathrm{~mm}$, utilizado para todos os três tipos de colunas. Para a modelagem das colunas híbridas, utilizou-se a montagem dos cabos foi feita com a barra de bambu na posição horizontal. O comprimento das barras espaçadoras para a primeira coluna híbrida foi de $820 \mathrm{~mm}$, e para a segunda coluna híbrida de $1320 \mathrm{~mm}$. E a localização das barras espaçadoras ao longo do eixo primcipal foi de 2100 e $3900 \mathrm{~mm}$, a partir da extremidade esbelda da barra do primeiro bambu, e 1700 e 3700 para a segunda barra de bambu, utilizadas na segunda coluna híbrida.

Foram comparadas duas situações teóricas, sendo a situação da coluna utilizando cabos de aço livres para deslizarem no apoio de parafuso dos espaçadores, e outra situação com os cabos clipados, impedidos desse deslizamento, constituindo assim dois modelos experimentais de colunas híbridas. Para ambos os casos teóricos, foram calculados numericamente os Diagramas de Southwell, com o objetivo de se obter a Carga de Euler do sistema proposto, observado em Chages (1974), obtida pelo inverso da inclinação da reta do diagrama. Para as colunas híbridas, numericamente foram aplicadas cargas de compressão de $10 \mathrm{kN}$ na primeira coluna, e $28 \mathrm{kN}$ e $35 \mathrm{kN}$ respectivamente para a segunda coluna em duas situações: sem a fixação dos cabos de aço, e com os mesmos fixados nas extremidades dos espaçadores.

A configuração das duas modelagens se apresenta nas Figuras 1, 2 e 3:

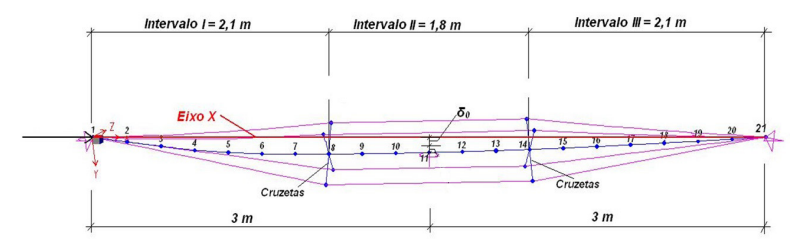

Figura 1. Modelagem da primeira coluna híbrida.

Fonte: o próprio autor.

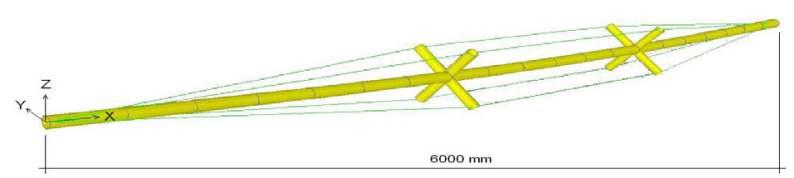

Figura 2. Configuração tridimensional da coluna.

Fonte: o próprio autor.

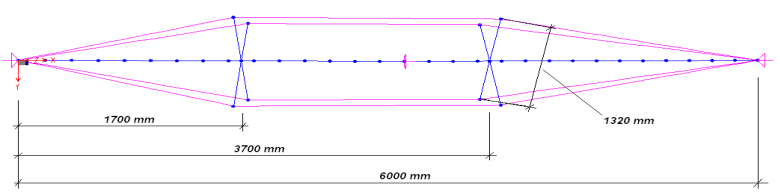

Figura 3. Modelagem da segunda coluna híbrida.

Fonte: o próprio autor.

Após esta construção e experimentação, observado em Moreira, Silva e Rodrigues (2011), foi projetada e modelada a coluna composta, utilizando fixação dos espaçadores por parafusos, com software para a modelagem, caracterizada por quatro 
Silva - Análisis estructural de tres columnas en bambú. Aplicaciones sostenibles en arquitectura.

barras paralelas de 5,5 metros de comprimento, conectadas descontinuamente por segmentos de bambu interpostos e fixos por parafusos de aço de $16 \mathrm{~mm}$ de diâmetro.

Os dois planos da aplicação dos parafusos têm inclinação de $45^{\circ} \mathrm{em}$ relação ao eixo y. Para uma correta organização das barras laterais de bambu, foi necessária a confecção de gabarito para fixação das mesmas, de modo a poder realizar os furos adequadamente, e posterior inserção dos parafusos para a montagem da coluna em questão.

A forma desta configuração geométrica para este tipo de coluna composta pode ser observada na Figura 4:

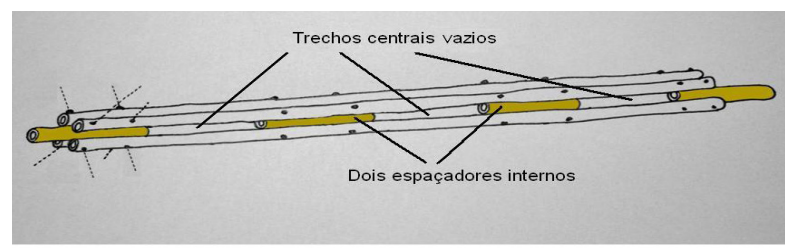

Figura 4. Esquema da alma descontínua com espaçadores internos. Fonte: o próprio autor.

Os espaçadores foram distribuídos a cada 1630 mm de distância entre suas seções centrais (Figura 5), ao longo do eixo central do protótipo, sendo fixos aos bambus laterais através de 4 barras roscadas.

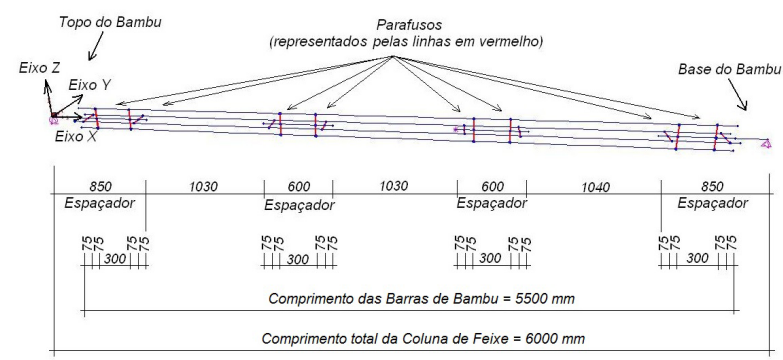

Figura 5. Dimensões da coluna composta estrutural. Fonte: o próprio autor.

Este tipo de coluna composta foi testada numericamente pelo software com cargas iniciais de $15 \mathrm{kN}$ (carga e descarga) e posteriormente até o limite previsto de $45 \mathrm{kN}$.

Para o terceiro tipo de coluna, chamada coluna de feixe de barras de bambu, foi modelada no software uma coluna que se consistiu de um segmento de bambu central chamado de alma, de $6 \mathrm{~m}$ de comprimento circundado por seis segmentos de bambu (conjunto este de barras denominado coroa). Foram comparadas por meio de algumas simulações, duas situações, sendo a primeira, que conduziu ao protótipo, com barras laterais de $3,6 \mathrm{~m}$ e a segunda, e após o teste de compressão, com barras laterais de $5,4 \mathrm{~m}$. Os bambus foram unidos por cintas de aço de $14,3 \mathrm{~mm}^{2}$ de área da seção, distribuídas ao longo do comprimento, de acordo com o pré-dimensionamento.

Na Figura 6, pode-se observar o projeto e a localização das cintas metálicas no conjunto desta coluna.

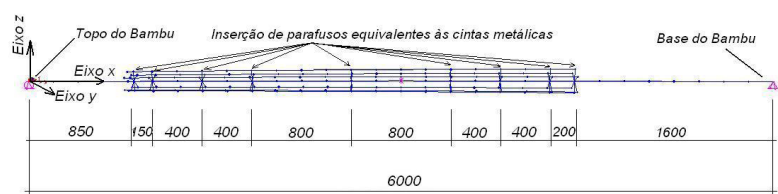

Figura 6. Projeto e localização das cintas metálicas na primeira coluna de feixe.

Fonte: o próprio autor.

E a Figura 7 apresenta o esquema da forma da coluna em feixe, com barras laterais em coroa envolta da barra central de bambu.

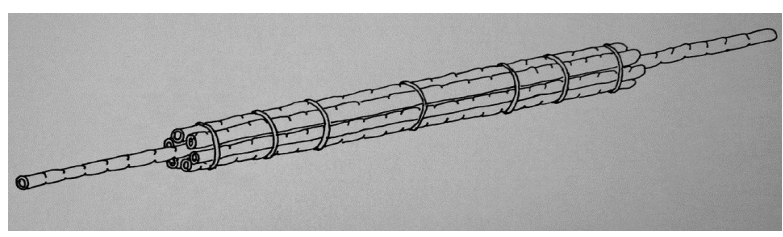

Figura 7. Esquema da forma da coluna em feixe.

Fonte: o próprio autor.

As colunas de feixe com laterais de barras de 3,6 metros, foram testadas numericamente com ciclos de cargas de $3 \mathrm{kN}$ até o limite previsto de $18 \mathrm{kN}$. Para as colunas com laterais de 5,4 metros, testadas com dois ciclos de cargas de $15 \mathrm{kN}$ (carga e descarga) e posteriormente até o limite de $35 \mathrm{kN}$. Para todas as modelagens numéricas, considerou-se o peso específico do material bambu igual a $7,9 \mathrm{kN} / \mathrm{m}^{3}$ (Tung, 2010), e o módulo de elasticidade de $11,9 \mathrm{GPa}$, valores médios obtidos para o lote de onde se retiraram os elementos do protótipo.

\section{Método de ensaio experimental}

Para os ensaios experimentais, tomaram-se como referências os procedimentos de ensaios em barras metálicas treliçadas, normalmente ocorridos no LAEES-UFMG, os quais fazem parte diversas pessoas com funções específicas durante 0 ensaio, além dos equipamentos necessários para captação e registros dos comportamentos dos materiais e sistemas analisados (Rodrigues, 2009). Quanto às funções, registraramse as seguintes atividades: aplicação de carga utilizando atuador hidráulico; leitura dos transdutores de deslocamentos localizados junto aos pontos centrais das colunas testadas; orientação para as aplicações de cargas; anotação dos deslocamentos obtidos após a carga aplicada; observação do software SAP2000 simulando a mesma carga aplicada junto ao experimento; registro fotográfico e de arquivos de vídeo do comportamento, deslocamento, e procedimentos de carga; realização de curva comportamental com software gráfico simultaneamente ao experimento. Pode-se observar que estes procedimentos contaram com sete pessoas, cada uma realizando uma função durante o experimento, entre técnicos do laboratório LAEES, alunos bolsistas do programa de Pós-Graduação em Engenharia de Estruturas e Graduação em Engenharia Civil, e professores do próprio Departamento, além do autor e orientador do projeto, e alunos e professores convidados.

Foram utilizados os pórticos de reação instalados no laboratório, constituído por dois pilares de aço com $6500 \mathrm{~mm}$ de distância um do outro, com bases enrijecidas parafusadas na laje de 
reação (solo). Para ancoragem do pórtico à laje de reação, foi utilizado um conjunto de parafusos, porcas e arruelas. A laje de reação tem $700 \mathrm{~mm}$ de espessura e armação adequada para suportar os esforços solicitantes provenientes do pórtico.

As etapas de aplicação de carga nas barras isoladas e diversas colunas ocorreram conforme realizado anteriormente nos ensaios numéricos referenciais. Optou-se por realizar aplicação de cargas em intervalos de $1 \mathrm{kN}$ para as barras isoladas de bambu, e de intervalos de $3 \mathrm{kN}$ para as colunas, de modo que pudesse ter o tempo necessário (cerca de 3 minutos entre uma aplicação de carga e outra) para a acomodação do sistema estrutural, quanto aos elementos constituintes, e que os ponteiros dos transdutores de deslocamentos tivessem em repouso após o movimento normal de registro.

Foi utilizado o Sistema de Aquisição de Dados (SAD) ADS 2000, da marca Lynx, com 16 canais independentes, ligado a um computador portátil, aparato padrão já utilizado no LAEES e conhecido pelos técnicos presentes. Nos ensaios foram utilizados os softwares AqDados 7.0.2 e AqAnalisys 7.0.2 (únicos existentes no Laboratório naquela ocasião) para aquisição e tratamento das informações.

Quanto aos testes de compressão no laboratório, todas as colunas construídas foram posicionadas horizontalmente, para se investigar a pior situação de uso, que nas estruturas têm inclinações que variam de 0 a 90 graus.

Foi projetado um adaptador para a extremidade, com ponta esférica, que gira dentro de um furo esférico fixo ao pórtico e ao atuador hidráulico, conseguindo-se um sistema bi rotulado. Para a detecção dos movimentos e comportamento das colunas durante os testes, foram posicionados três transdutores de deslocamentos conforme se observa na Figura 8, DT-1 e DT-3 horizontalmente e DT-2 verticalmente (no caso da coluna composta) e a 45 graus (no caso das colunas híbridas e de feixe de bambu). Junto ao atuador hidráulico de operação manual, instalou-se uma célula de carga de $100 \mathrm{kN}$, observada na Figura 9. Todos os equipamentos indicados foram conectados ao sistema para aquisição de dados, em tempo real durante os ensaios, citado acima.

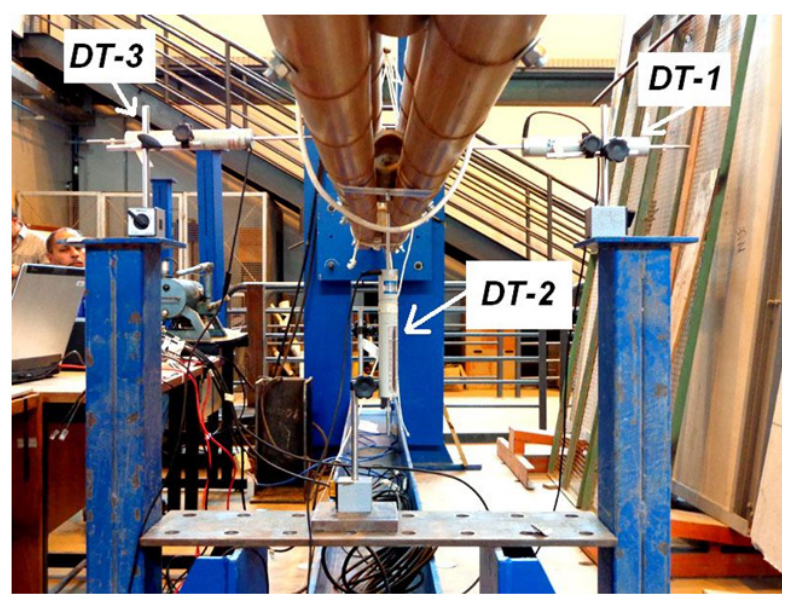

Figura 8. Instalação dos transdutores de Deslocamentos (DTs). Fonte: o próprio autor.

Após as análises das modelagens de todas as colunas (híbridas, compostas e de feixe), foram construídas as colunas conforme a descrição a seguir, e após, apresentam-se os resultados dos ensaios realizados.

82 Procesos

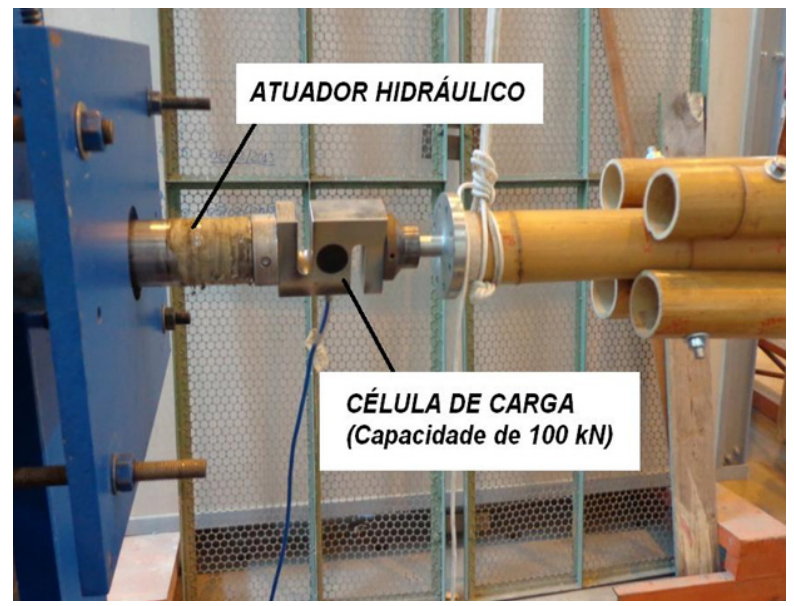

Figura 9. Instalação do atuador hidráulico e da célula de carga. Fonte: o próprio autor.

\section{Construção das colunas propostas}

A partir da modelagem numérica, foram construídas as colunas híbridas com cabos de aço. Para a sequencia da construção, optou-se por sistemas de gabaritos, de modo que o processo fosse otimizado com a estabilidade das barras uma em relação às outras no momento de perfuração para ser inserido as barras rosqueadas em sua construção, como se pode observar na Figura 10. A Figura 11 apresenta a configuração final da coluna híbrida com a instalação dos cabos de aço, inicialmente apoiados nas barras rosqueadas junto aos espaçadores. Após esta fase, foram confeccionados os clips para fixação dos cabos de aço junto às barras rosqueadas. Esses clips são constituídos de duas barras metálicas planas de $3 \mathrm{~mm}$ de espessura (Figura 12).

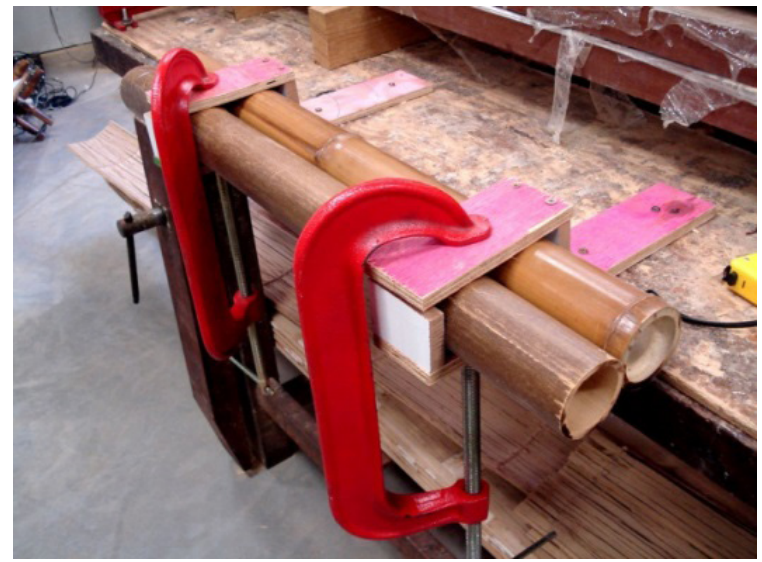

Figura 10. Sistema de gabaritos para furos dos bambus. Fonte: o próprio autor.

Foi utilizada uma rosca com o mesmo diâmetro da barra rosqueada cortada ao meio, para que se encaixe perfeitamente na barra rosqueada. Outra rosca de menor diâmetro também foi cortada ao meio para se encaixar pelo seu diâmetro à lateral do cabo de aço. As roscas foram soldadas às placas metálicas Figuras 13, 14. 
Silva - Análisis estructural de tres columnas en bambú. Aplicaciones sostenibles en arquitectura.

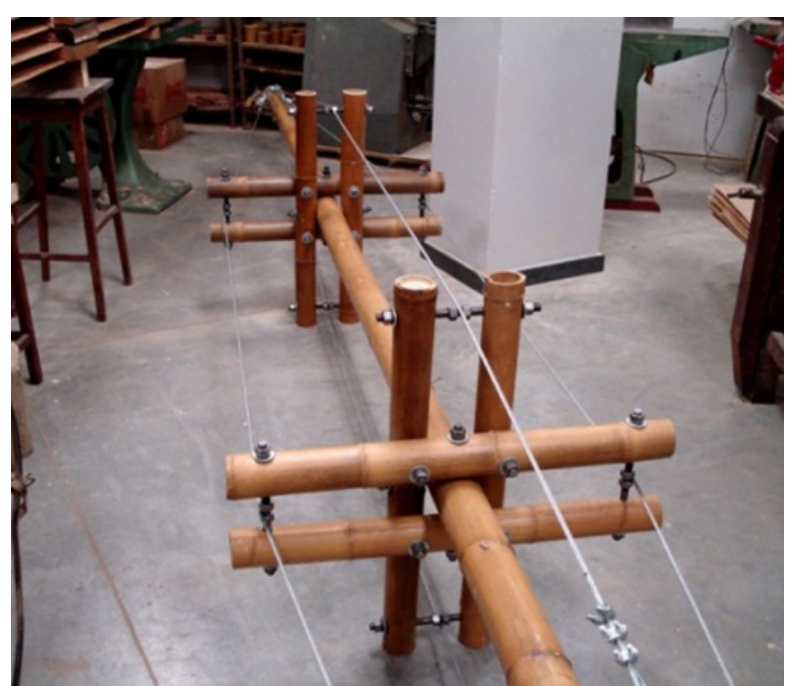

Figura 11. Configuração final da coluna híbrida. Fonte: o próprio autor.

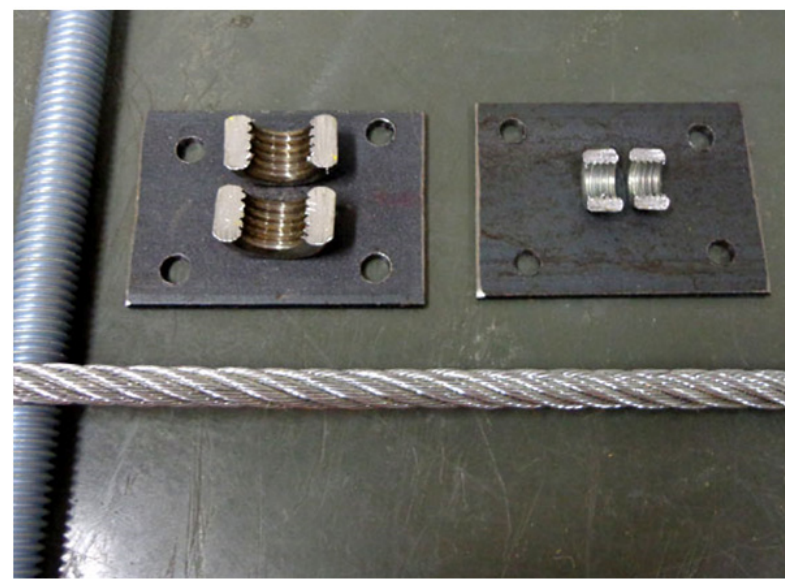

Figura 12. Peças do clip desenvolvido.

Fonte: o próprio autor

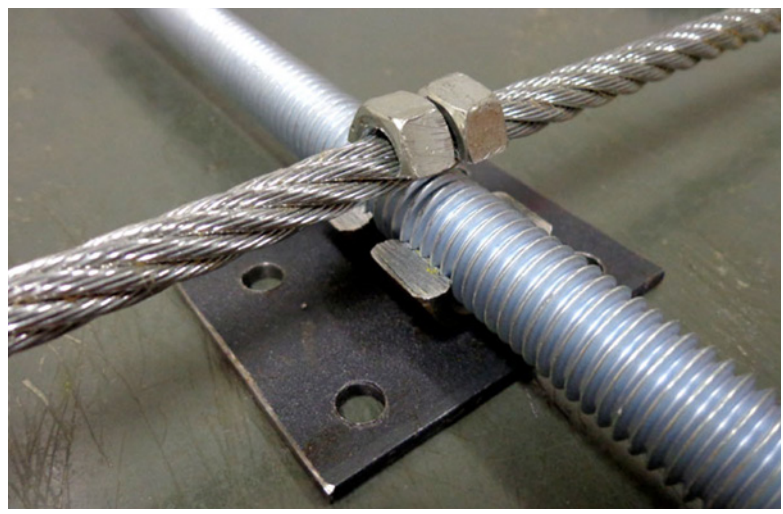

Figura 13. Sequencia de instalação e montagem do clip no cabo de aço. Fonte: o próprio autor.

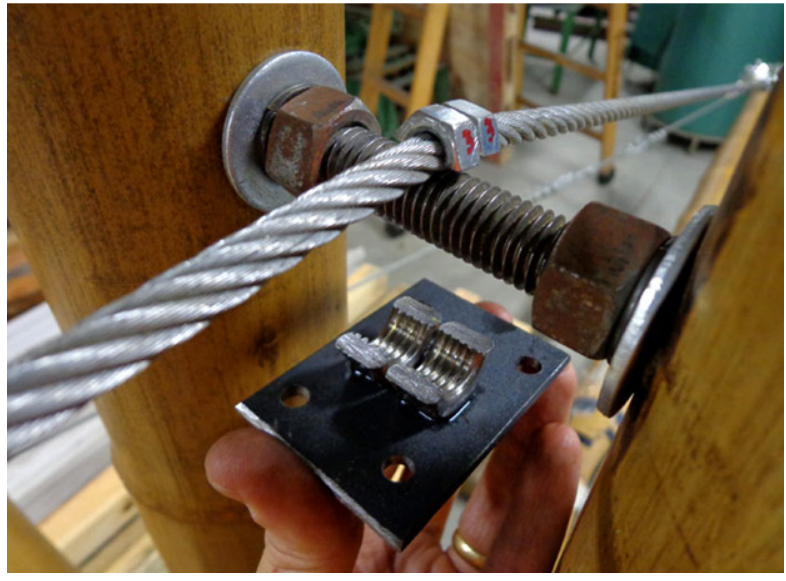

Figura 14. Sequencia de instalação e montagem do clip no cabo de aço Fonte: o próprio autor.

Nas Figuras 15 e 16, pode-se observar a configuração final do clip montado para fixação dos cabos de aço.

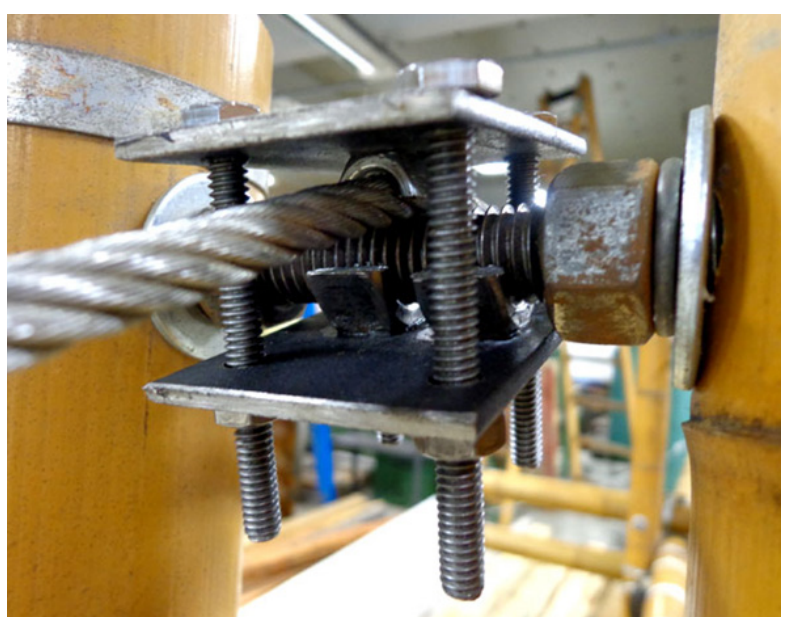

Figura 15. Vistas interna e perspectiva do clip fixando o cabo de aço. Fonte: o próprio autor.

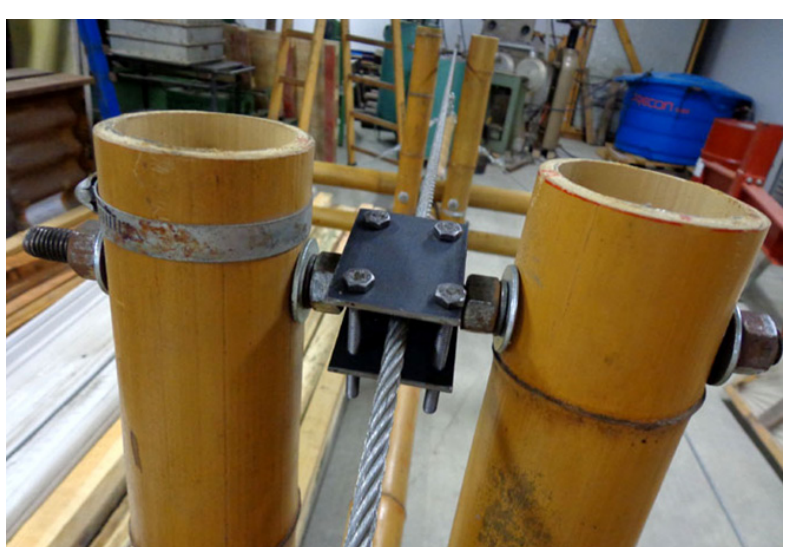

Figura 16. Perspectiva do clip fixando o cabo de aço. Fonte: o próprio autor. 
Para a coluna composta, foram necessários alguns gabaritos de estabilidade das barras de bambu para o momento de perfuração simultaneamente de várias barras e alguns apoios laterais, como se observa nas figuras 17 e 18.

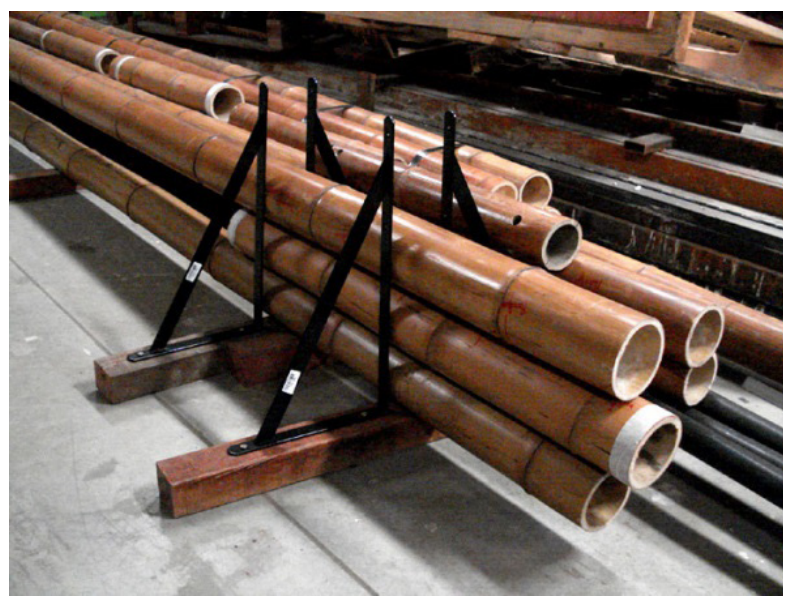

Figura 17. confecção de gabarito e pontos de apoio das barras. Fonte: o próprio autor.

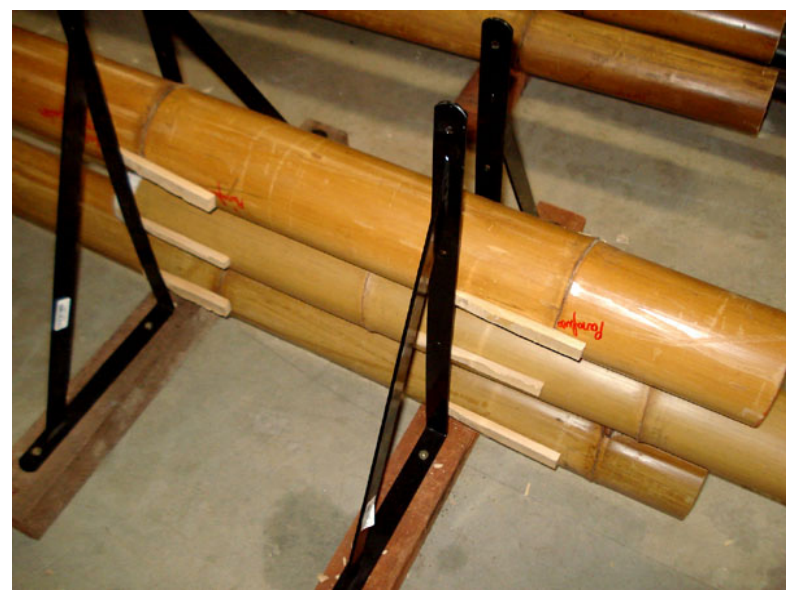

Figura 18. confecção de gabarito e pontos de apoio das barras. Fonte: o próprio autor.

No caso da coluna de feixe, as Figuras 19 e 20 mostram os processos de fabricação da coluna utilizando-se de uma máquina que puxa a cinta metálica de aço inoxidável de sessão de 19,02 mm × 0,75 mm (14,26 mm²), para dar a tensão, e a corta em seguida. O processo é finalizado com a instalação de um clip que trava o cintamento.

A figura 21 apresenta um aspecto da coluna montada com as cintas metálicas ao seu redor.

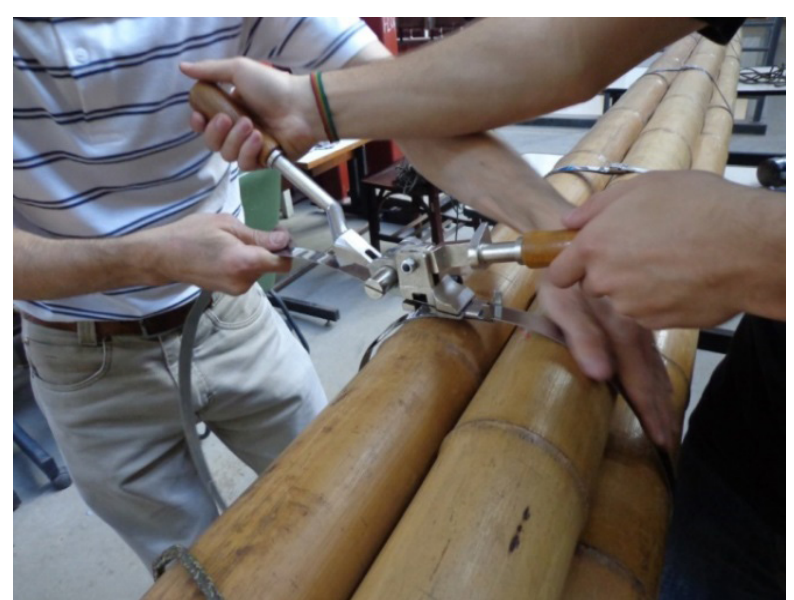

Figura 19. instalação cinta metálica e da trava na cinta ao redor da coluna. Fonte: o próprio autor.

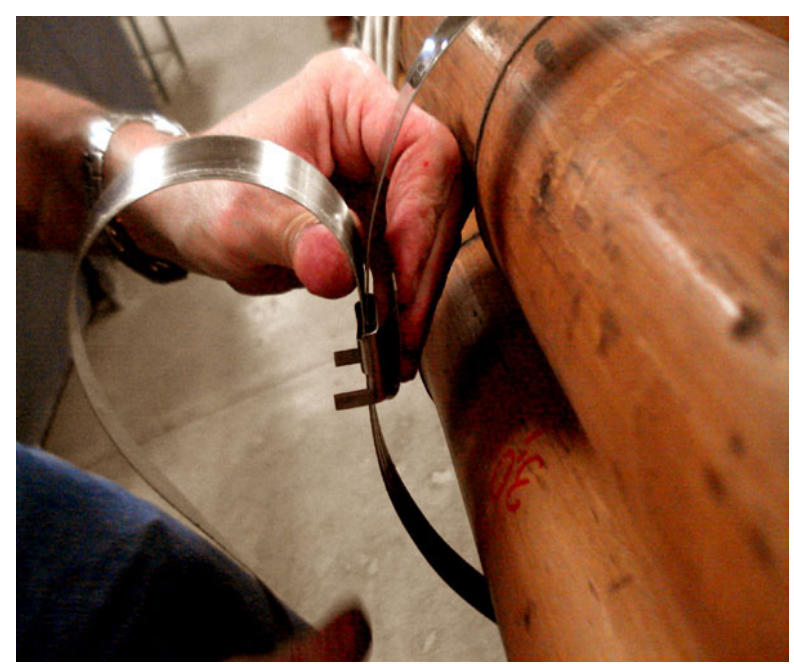

Figura 20. instalação cinta metálica e da trava na cinta ao redor da coluna. Fonte: o próprio autor.

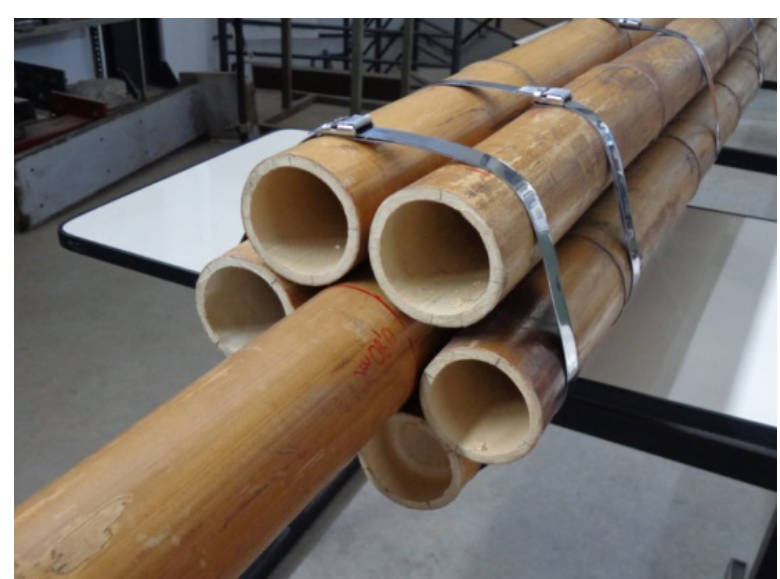

Figura 21. Aspecto da coluna montada com as cintas metálicas ao redor da mesma.

Fonte: o próprio autor. 
As figuras 22 e 23 apresentam a instalação dos transdutores de deslocamento (DT) e a instalação da chapa equalizadora na lateral central da coluna de feixe, para receber a haste do DT para a medição.

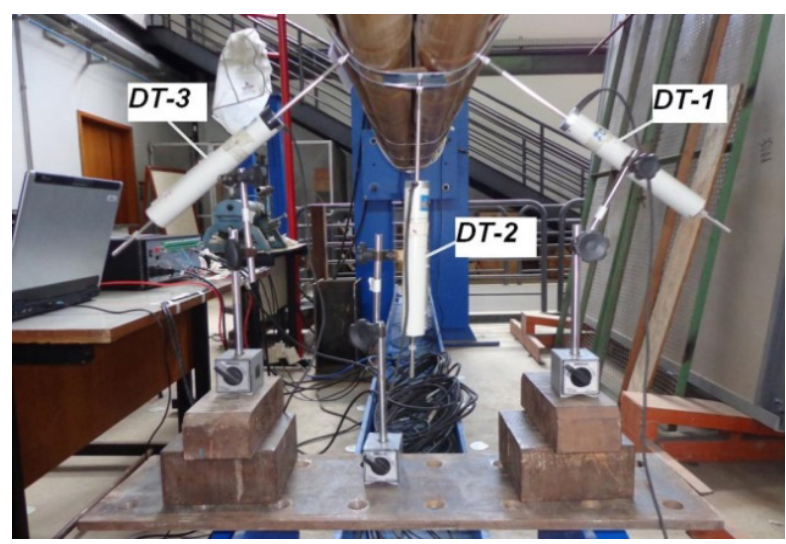

Figura 22. Instalação dos DT e da chapa equalizadora. Fonte: o próprio autor.

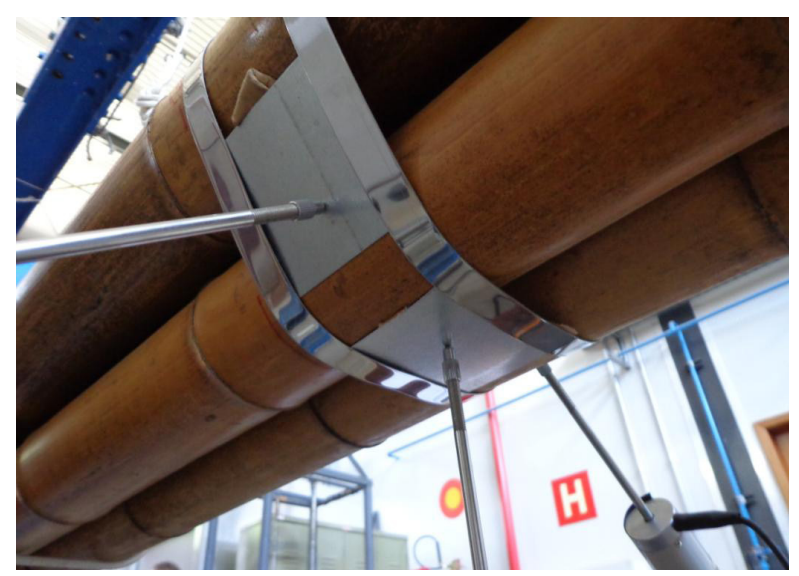

Figura 23. Instalação dos DT e da chapa equalizadora. Fonte: o próprio autor.

\section{Resultados e Discussões}

Apresentam-se neste tópico, os resultados e discussões dos testes com base nas análises numéricas e experimentais de laboratórios, para os três tipos de colunas: híbridas, compostas e de feixe.

\section{Colunas híbridas: resultados}

Com a coluna construída, passou-se à fase seguinte que foi a montagem no pórtico e instalação dos instrumentos de medição e Sistema de Aquisição de dados para o ensaio mecânico de compressão.

Realizadas as simulações numéricas para a coluna híbrida com espaçadores de $820 \mathrm{~mm}$, e o ensaio experimental no laboratório, tem-se a sobreposição da curva carga $x$ deslocamento (PDelta) apresentado pela Figura 24. Pelo Diagrama de Southwell, podese calcular a Carga de Euler $\left(F_{E}\right)$ do sistema proposto. A Figura 25 apresenta o diagrama experimental, resultando nos valores de carga limite do sistema de $12,4 \mathrm{kN}$ (experimental). Ressaltase que o valor desta carga para o resultado numérico apresentou $13,0 \mathrm{kN}$, validando o resultado.

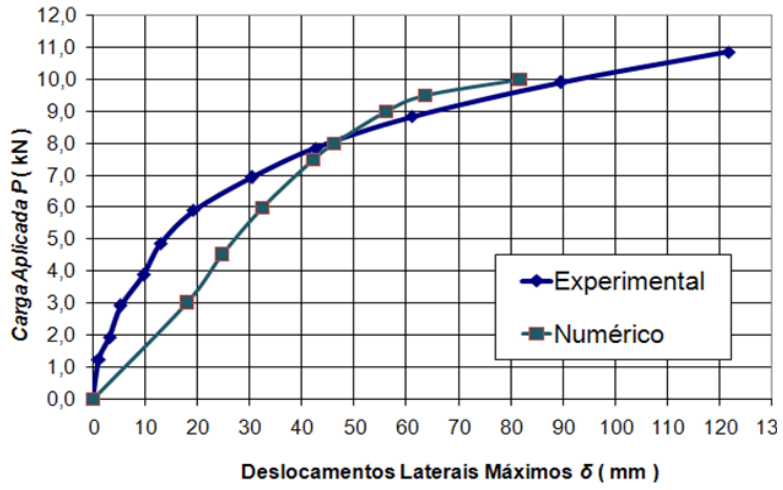

Figura 24. Sobreposição das curvas PDeltas. Fonte: o próprio autor.

DIAGRAMA DE SOUTHWELL

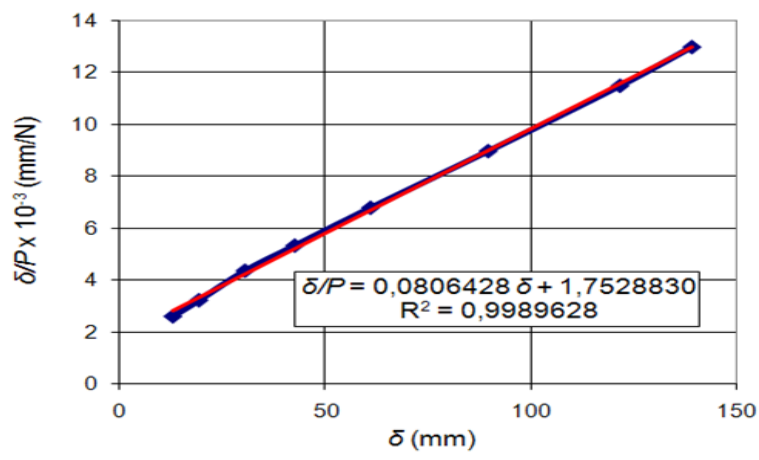

Figura 25. Diagrama de Southwell. Fonte: o próprio autor

Após estes testes e ensaio, construiu-se a coluna híbrida com espaçadores maiores (de $1320 \mathrm{~mm}$ ) e melhor localizados em relação à barra central. Os resultados são apresentados na Figura 26. Pelo Diagrama de Southwell, a Carga de Euler $\left(F_{E}\right)$ desta nova coluna proposta, numericamente foi de $31,94 \mathrm{kN}$ e $30,1 \mathrm{kN}$ pelo ensaio experimental. Como os cabos de aço estavam livres para deslizar nas extremidades dos espaçadores, optouse por fixá-los por um sistema de clips metálicos, de modo a enrijecer o sistema. Após o processo de fixação, apresentaramse os resultados: $37,7 \mathrm{kN}$ calculado experimentalmente e $32,1 \mathrm{kN}$ numericamente.

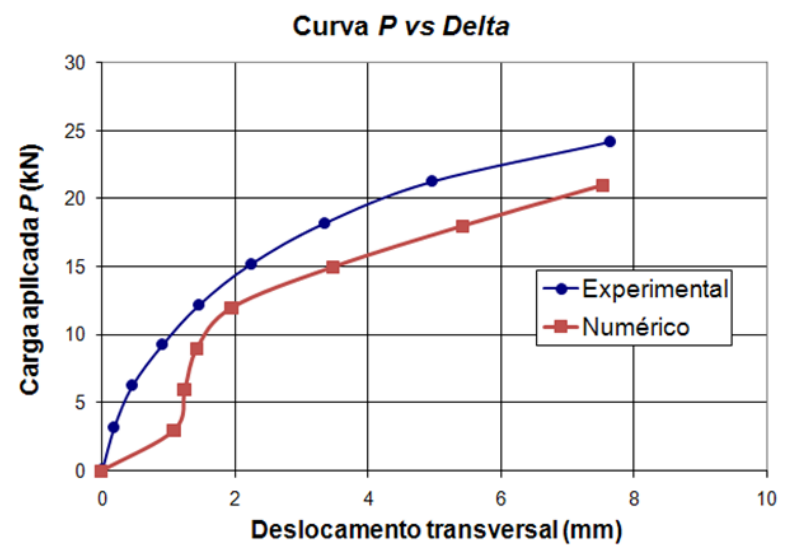

Figura 26. Curvas PDelta e comparação experimental e numérica. Fonte: o próprio autor 
Na Figura 27 observa-se as duas curvas PDelta da coluna híbrida clipada, com aumento de resistência em $25 \%$, além de deslocamento máximo no centro da coluna de apenas $6 \mathrm{~mm}$.

Comparação Carga x Deslocamento da Coluna Sem Clip e Com Clip (Experimental)

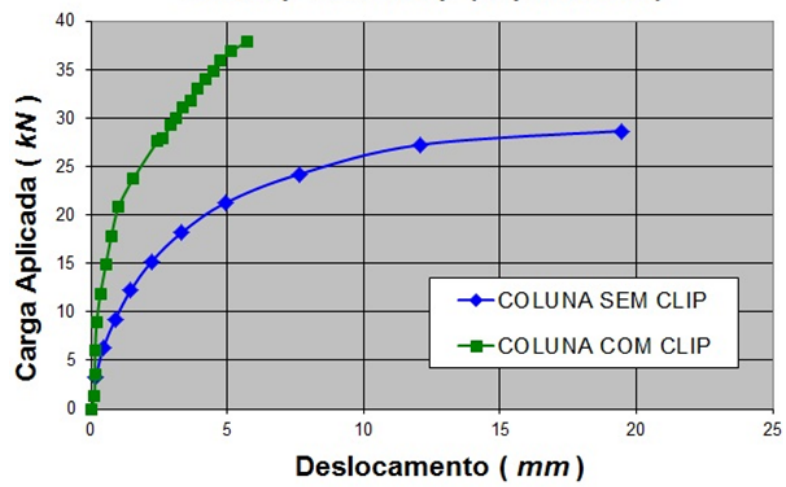

Figura 27. Comparação do comportamento da coluna com e sem clip. Fonte: o próprio autor

Comparando os resultados numéricos e experimentais, os dados se apresentaram muito consistentes, mostrando-se que o uso dos clips de fixação torna-se um aparato eficiente que aumenta a força limite da coluna e que a coluna é uma alternativa eficaz na elaboração de estruturas arquitetônicas leves, fáceis de serem construídas e muito resistentes, podendo substituir elementos metálicos em tensionadas (Figuras 28 e 29).

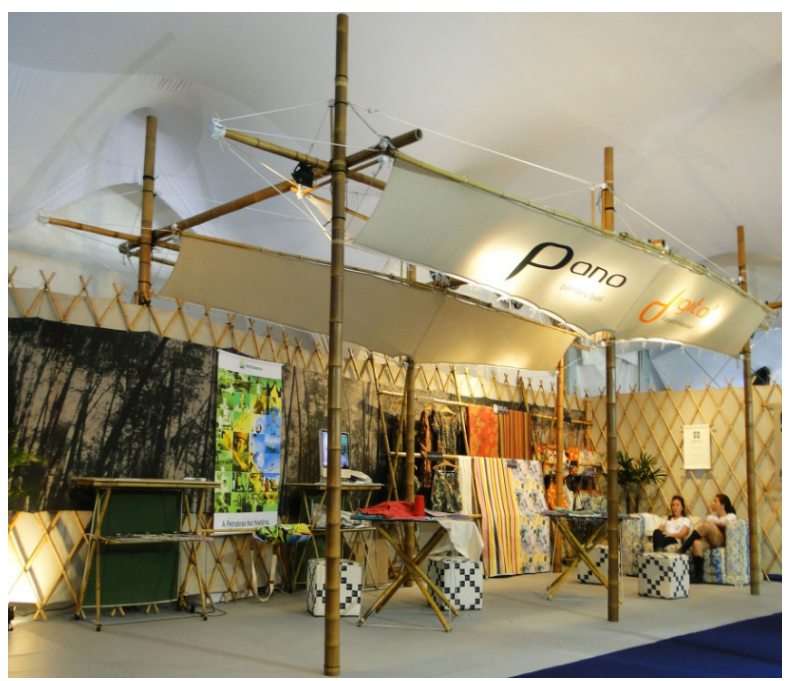

Figura 28. Estruturas de bambu utilizadas em tensionadas. Fonte: Bambutec.com.br, e Estação Rosa Park em Michigan (EUA)

\section{Colunas compostas: resultados}

Com o objetivo de se modelar a estrutura da coluna de modo mais prático, optou-se por identificar se a inércia das seções das barras de bambu (que normalmente são variáveis de acordo com o diâmetro e a espessura local) poderia ser trabalhada com uma inércia constante, para todas as seções da barra. Assim, foram realizadas modelagens tanto com inércia variável quanto constante, para comparação e validação dos resultados. A partir das simulações numéricas realizadas para as colunas compostas e os ensaios experimentais no laboratório, temse a sobreposição da curva carga $\mathrm{x}$ deslocamento (PDelta) apresentado pela Figura 30.

86 Procesos

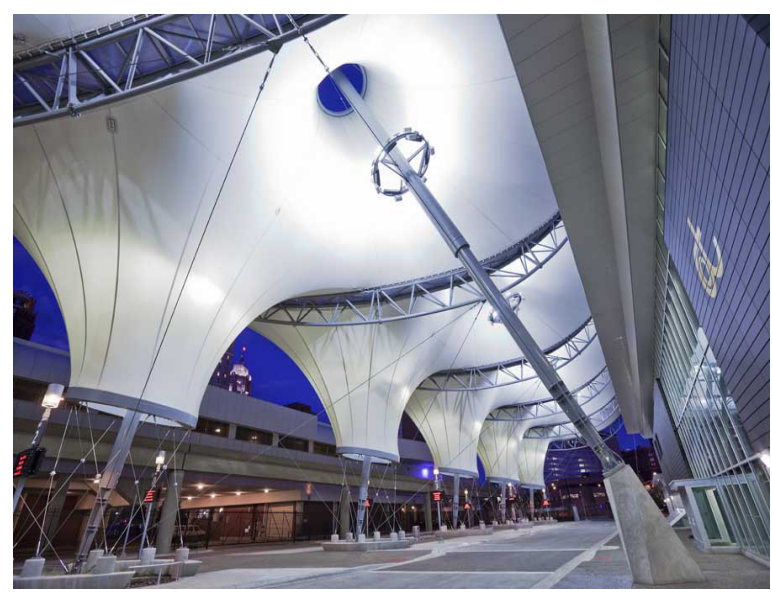

Figura 29. Estruturas metálicas utilizadas em tensionadas. Fonte: Bambutec.com.br, e Estação Rosa Park em Michigan (EUA)

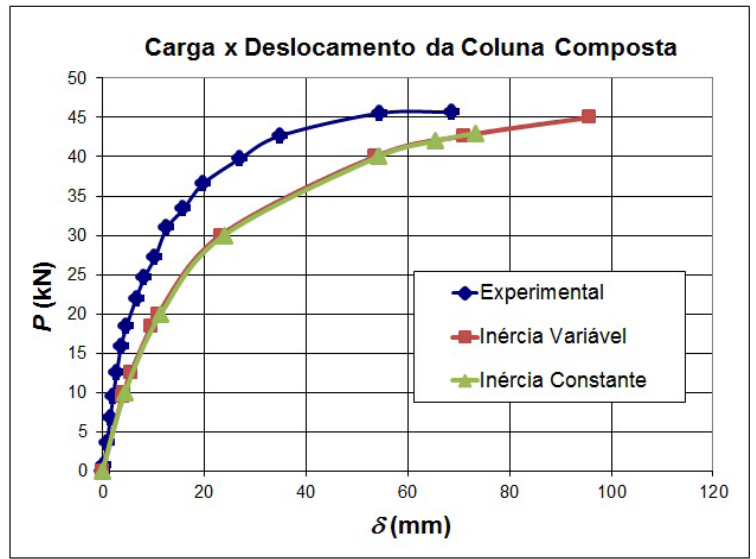

Figura 30. Sobreposição das curvas PDeltas para a coluna composta. Fonte: o próprio autor.

A carga limite aplicada no ensaio experimental desta coluna chegou a 45,68 kN, com deslocamento lateral de $65 \mathrm{~mm}$. O Diagrama de Southwell apresentou carga limite de $F_{E}=54,40$ kN. Para a simulação numérica, obteve-se $54,55 \mathrm{kN}$, com uma diferença de apenas 0,2 \%, validando o sistema trabalhado. Durante o descarregamento no momento final do ensaio, pode-se observar que o sistema apresentou um deslocamento residual de $7,86 \mathrm{~mm}$, que muito provavelmente representa as deformações plásticas ocorridas por concentração das tensões nos furos dos parafusos, além de deformações viscosas não recuperadas.

Supondo-se que o ponto de momento máximo situe-se a uma distância $X$ do apoio, pode-se então estabelecer outra condição para a carga limite, ou seja, as tensões de compressão máximas na seção mais solicitada. Após uma criteriosa avaliação das tensões de compressão máximas ocorridas no ponto de maior solicitação, obteve-se um resultado de tensão de $30 \mathrm{MPa}$, o que representa valor muito aquém do limite de resistência à compressão paralela, que é igual a $80 \pm 9 \mathrm{MPa}$ (Moreira e Ghavami, 2011).

Observou-se também que o estado limite da coluna ensaiada ficou estabelecido pelo esmagamento dos furos, inclusive detectado visualmente durante os ensaios, para a carga de 
compressão igual a $83 \%$ da Carga de Euler $\left(P=0,83 F_{E}\right)$. O ajuste da modelagem numérica ao experimento possibilitou estudos paramétricos, relativamente independentes de novos experimentos mecânicos, de onde se podem extrair curvas de dimensionamento para colunas compostas em geral. Identificou-se que este tipo de coluna é capaz de ser construída com outros diâmetros e espessuras de bambu.

Exemplos de aplicação deste tipo de coluna composta: foram utilizadas para a construção de uma capela, cenário da novela televisiva Araguaia, da Rede Globo de Televisão em 2010 (Figuras 31 e 32), onde a edificação contou com análise e dimensionamento estrutural da UFMG, tendo sido a principal motivação para a investigação realizada durante os experimentos com este tipo de coluna; e também no Centro de Educação Ambiental (Sindicato Professores SINPRO-DF), Figura 33.

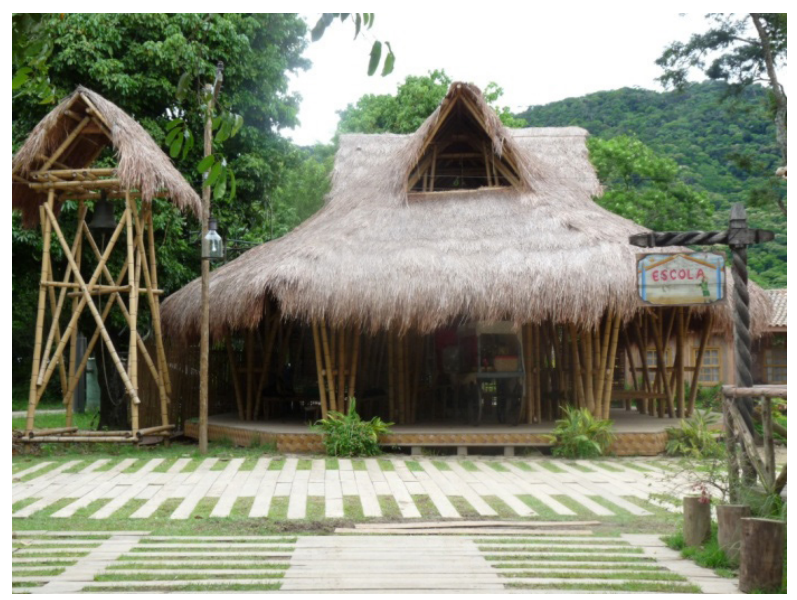

Figura 31. Aspecto da capela do cenário, e uso de colunas compostas Fonte: Arte Desenho Construtora, Rio de Janeiro, RJ.

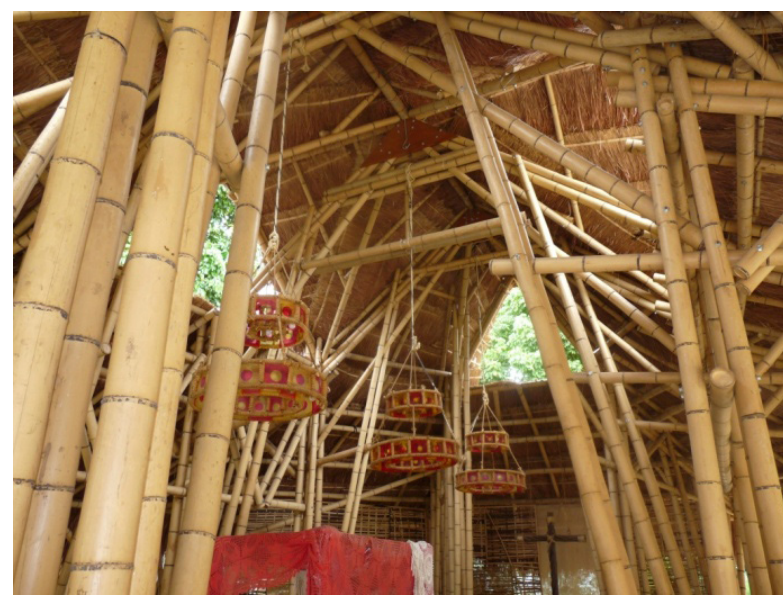

Figura 32. Aspecto da capela do cenário, e uso de colunas compostas Fonte: Arte Desenho Construtora, Rio de Janeiro, RJ.

Cabe à Engenharia agregar conhecimento às soluções utilizadas, em muitos casos são soluções intuitivas, garantindo economia de materiais, porém condicionada à segurança das edificações em uso, num determinado contexto. Aí está o grande desafio de se usar bambu em seu estado natural.

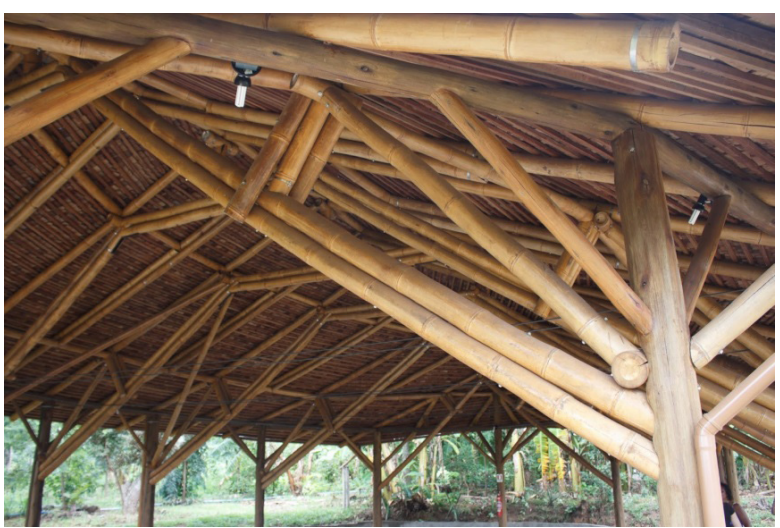

Figura 33. Colunas compostas utilizadas no Sindicato Professores SINPRO-DF.

Fonte: Centro de Educação Ambiental, Sindicato Professores - SINPRO-DF.

\section{Colunas de feixe: resultados}

Observou-se que embora este tipo de coluna consuma um número relativamente alto de bambus, se comparados com as demais colunas testadas por Moreira, Silva e Rodrigues (2011), a facilidade construtiva e a possibilidade de uso de bambus de menor diâmetro, são vantagens que se agregam a este produto, observado em Silva Rodrigues e Moreira (2014).

Durante o ensaio de compressão da coluna de feixe com laterais de $3600 \mathrm{~mm}$, com o auxílio de uma caneta de raio laser comum, instalada na extremidade da borda de uma das barras do feixe lateral, apontando-se o raio de luz para a outra borda da outra extremidade da mesma barra, e medindo-se o deslocamento da superfície do bambu, em relação a este mesmo raio, pode-se observar e medir a deflexão central das barras laterais do mastro. Esse deslocamento foi da ordem de $20 \mathrm{~mm}$ aproximadamente, considerando-se apenas as barras de $360 \mathrm{~mm}$ de comprimento, utilizadas para a construção do feixe lateral. Como a deflexão máxima foi de $120,5 \mathrm{~mm}$, significa que a maior contribuição para a deflexão foi proveniente das extremidades livres, $100,5 \mathrm{~mm}$, o que demonstrou a necessidade de se aumentar o comprimento dos bambus laterais, passando de 3600 para $5400 \mathrm{~mm}$, que foi a medida adotada para a construção da segunda coluna de feixe.

A partir dos resultados, foram traçados os Diagramas de Southwell, com o objetivo de se obter a Carga de Euler do sistema proposto de colunas com barras laterais de $3600 \mathrm{~mm}$ e $5400 \mathrm{~mm}$, e os deslocamentos laterais obtidos, em acréscimo à imperfeição inicial, a partir de carga aplicada de $18 \mathrm{kN}$ e $28 \mathrm{kN}$ respectivamente às colunas.

As Figuras 34 e 35 apresentam os Diagramas de Southwell de ambos os casos. A diferença no comportamento das duas colunas foram de carga limite de utilização de $F_{E}=19,23 \mathrm{kN}$ e $F_{E}$ $=39,84 \mathrm{kN}$ respectivamente, aplicando-se o cálculo do inverso da inclinação da reta. Quanto às imperfeições iniciais, calculouse $18,8 \mathrm{~mm}$ para a primeira coluna e $17,8 \mathrm{~mm}$ para a segunda coluna, de modo que estes valores se aproximam da imperfeição inicial aplicada numericamente de $20 \mathrm{~mm}$ em cada coluna.

Após estes valores identificados, foram construídas e testadas as colunas de feixe, tanto com barras menores de $3600 \mathrm{~mm}$ quanto à coluna com barras laterais maiores, de $5400 \mathrm{~mm}$. 


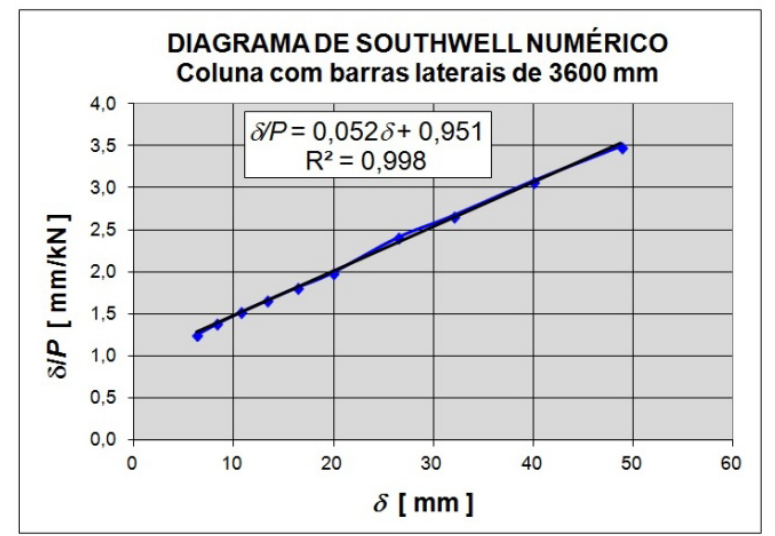

Figura 34. Diagrama de Southwell (numérico): barras de 3600 mm. Fonte: o próprio autor.

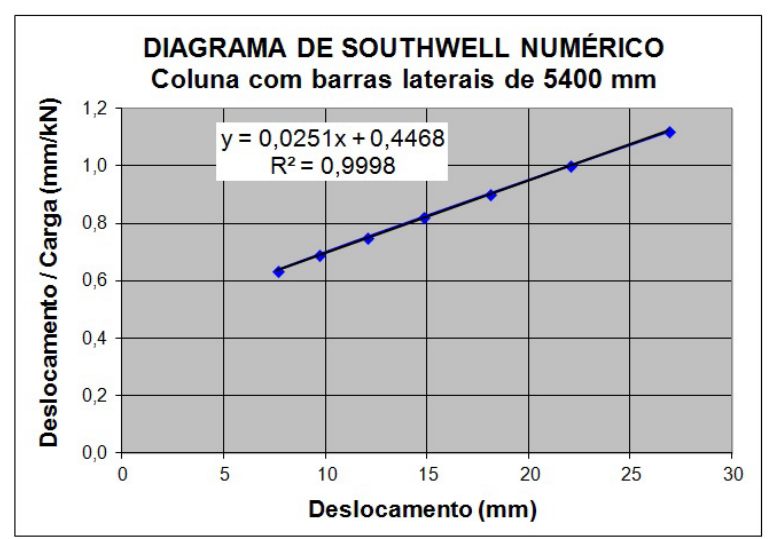

Figura 35. Diagrama de Southwell (numérico): barras de $5400 \mathrm{~mm}$. Fonte: o próprio autor.

Com os ensaios de compressão realizados, obtiveram-se os resultados com Diagramas de Southwell, nas Figuras 36 e 37.

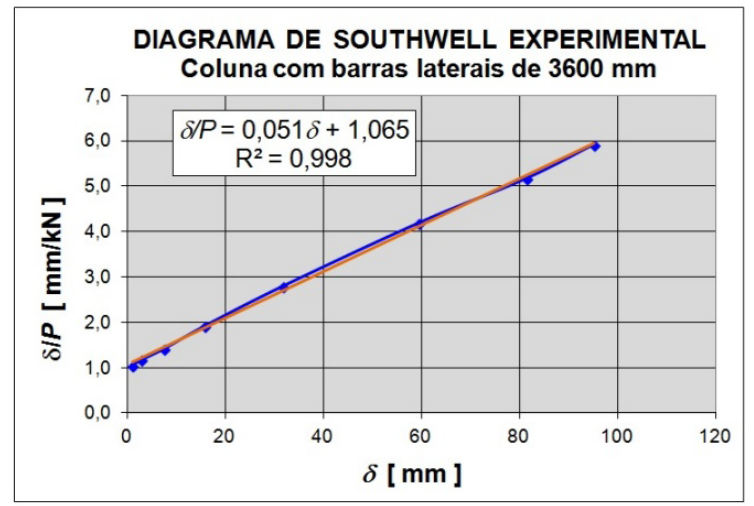

Figura 36. Diagrama de Southwell (experimental): barras de $3600 \mathrm{~mm}$. Fonte: o próprio autor.

Observando os Diagramas de Southwell de ambos os casos, tem-se que a coluna de feixe com barras laterais de $3600 \mathrm{~mm}$ apresentou uma carga limite de utilização de $F_{E}=19,6 \mathrm{kN}$, muito próximo ao resultado numérico identificado (apenas 1,9\% de diferença maior) e a segunda coluna ensaiada apresentou $F_{E}=$ 46,56 kN, 16,84 \% maior que o numérico.

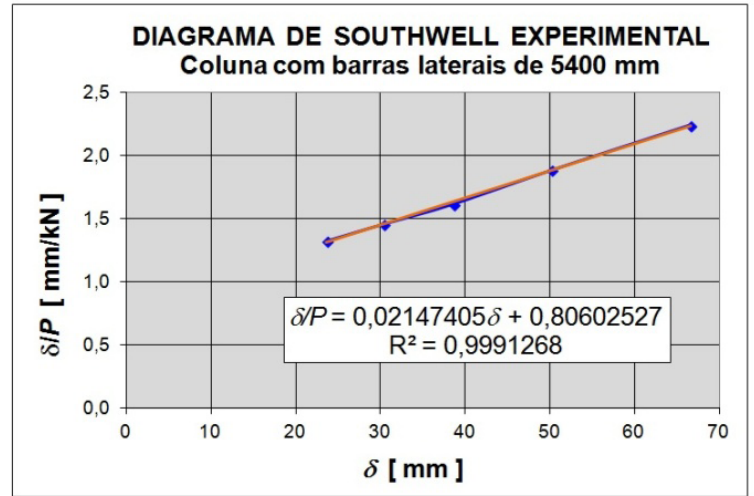

Figura 37. Diagrama de Southwell (experimental): barras de $5400 \mathrm{~mm}$. Fonte: o próprio autor.

Essa maior rigidez pode ser atribuída ao menor diâmetro do parafuso que representa a cinta metálica da coluna de feixe, utilizado no software, que precisou ser recalculado para aferir o sistema. Quanto às imperfeições iniciais, calculou-se 20,88 mm para a primeira coluna e $37,53 \mathrm{~mm}$ para a segunda coluna, o que mostra que a segunda coluna devido ao peso próprio tendeu a ter um deslocamento inicial maior no centro da coluna e ao possível deslizamento de uma barra de bambu em relação às demais da coluna construída.

Corrigidos os fatores de construção, quanto ao diâmetro dos parafusos equivalentes à cinta metálica, os valores apresentados pelas simulações em relação aos ensaios experimentais também se mostraram equivalentes, validando o experimento e os dados obtidos permitindo estudos paramétricos futuros, tanto as simulações e modelagens realizadas com inércia variável para cada seção das barras de bambu quanto modelagens com inércia constante. Resultado de carga de Euler experimental: $F_{E}=46,56$ $\mathrm{kN}$, enquanto que na modelagem numérica apresentou $\mathrm{FE}=45,05$ kN. E imperfeição inicial experimental foi calculada em $37,53 \mathrm{~mm}$, enquanto que numericamente se obteve $19,59 \mathrm{~mm}$. A Figura 38 mostra a comparação numérica e experimental do comportamento desta coluna.

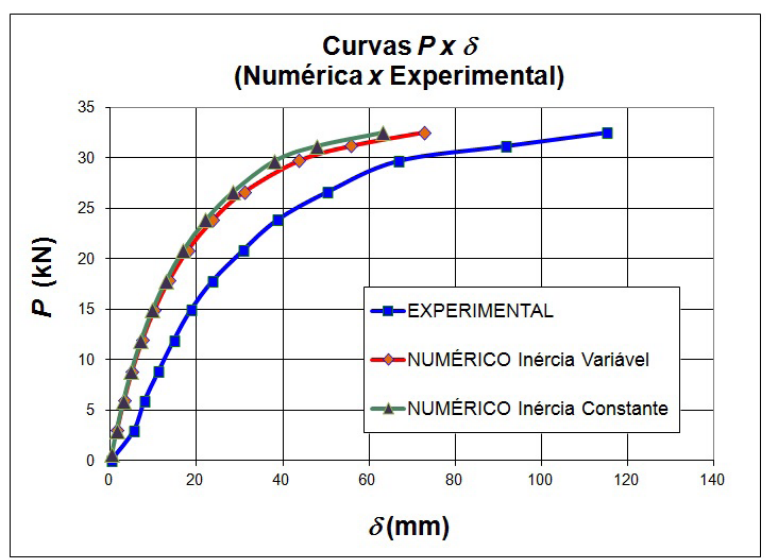

Figura 38. Comparação $\mathrm{P}$ x Delta numérico e experimental. Fonte: o próprio autor.

Quanto às tensões máximas no centro da barra denominada alma, desta coluna, foi calculado valor máximo de 34,2 MPa. Essas tensões, ainda que elevadas, situam-se bem abaixo das tensões limites de resistência do lote dos bambus que compõem a coluna (de $80 \pm 9 \mathrm{MPa}$ ). 
Como exemplo de aplicação desse tipo de composição de barras em feixe, as Figuras 39 e 40 apresentam o projeto arquitetônico e construção do Instituto Kairós, Nova Lima (MG), com design de componentes, distribuição dos pórticos, análise e dimensionamento estrutural da UFMG. Os bambus utilizados na construção foram da espécie Phyllostachys aurea, com cinco $\mathrm{cm}$ de diâmetro médio.

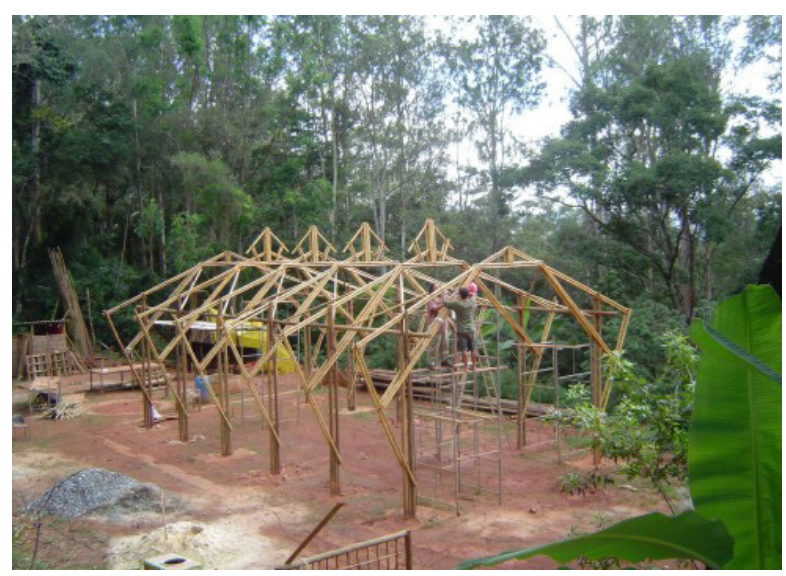

Figura 39. Exemplo de aplicação de colunas em feixe em estrutura. Fonte: Instituto Kairós, Distrito de Macacos, Nova Lima (MG)

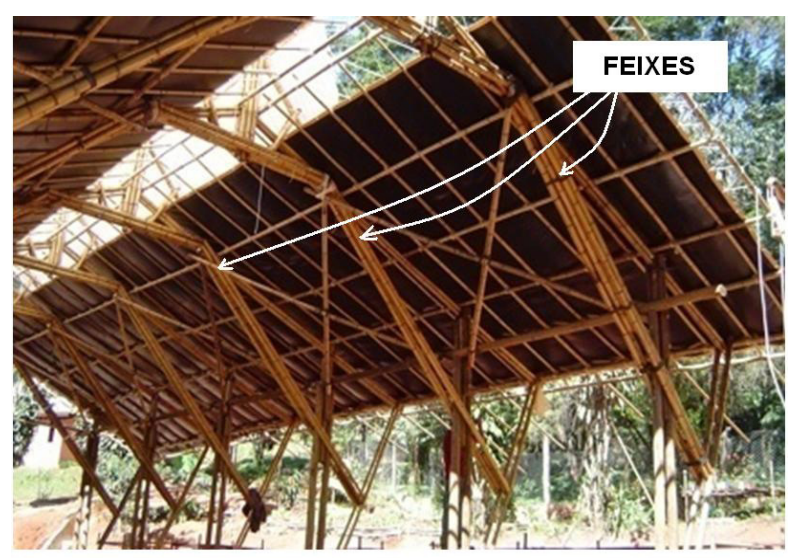

Figura 40. Exemplo de aplicação de colunas em feixe em estrutura. Fonte: Instituto Kairós, Distrito de Macacos, Nova Lima (MG).

Vários conceitos foram experimentados nesta estrutura, como elementos em feixe, design das ligações parafusadas e estruturas mistas com eucalipto, entre outros. Outro exemplo são as colunas em feixe, utilizadas em toda a construção da Sala Conferências Naman Retreat, Vietnã (Figura 41).

\section{Conclusões}

O presente trabalho apresentou resultados de análise numérica e testes de compressão em colunas de bambu, nos formatos híbrido, composto e de feixe, utilizando-se além de barras de bambu, materiais diversos como cabos de aço, cintas metálicas, parafusos e acessórios de fixação, buscando estabelecer estados-limites de serviço e conhecer os comportamentos dessas colunas em possíveis situações de uso.

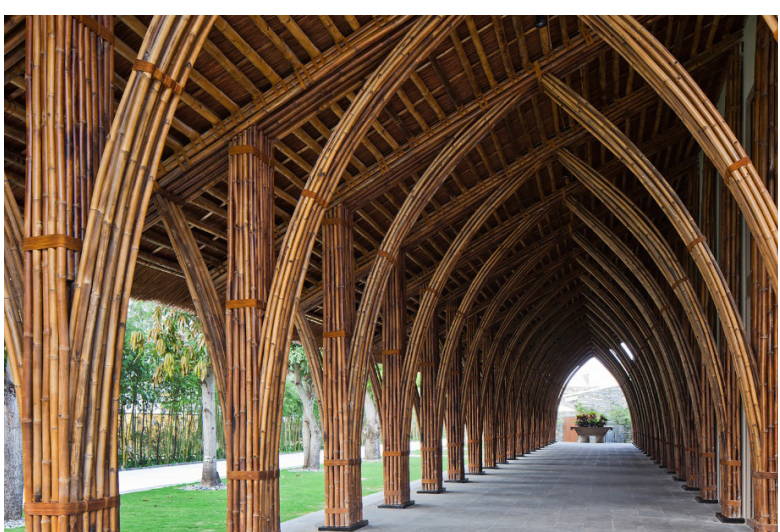

Figura 41. Uso de colunas em feixe, Sala de Conferências Naman Retreat, Vietnã Fonte: Vo Trong Nghia Architects.

Com os ensaios das colunas híbridas, observou-se também a necessidade de fixação dos cabos de aço junto às seções extremas dos espaçadores, o que levou ao desenvolvimento de sistemas de conexão entre eles, denominado clip dos cabos de aço, aumentando consideravelmente a carga limite de utilização.

Outro fator importante na análise das colunas construídas e ensaiadas foi a utilização do Diagrama de Southwell para análise da força axial de flambagem global (conhecida como Carga de Euler), sendo a força limite do sistema, e que possibilita também conhecer a imperfeição inicial do sistema, permitindo maior segurança à aplicação de carga nos ensaios das colunas.

Para as colunas compostas, pôde-se constatar o grande desempenho frente às colunas híbridas, visto a capacidade de carga que se aproximou de $45 \mathrm{kN}$ com mesmo comprimento útil de seis metros e deflexão lateral de apenas $70 \mathrm{~mm}$. No entanto, pode-se observar que a força limite da coluna ficou restrita pelo esmagamento dos furos na barra do bambu da extremidade de menor diâmetro e espessura de parede, detectado visualmente durante o ensaio, e também pelas tensões de contato. Para este caso, sugere-se que os parafusos utilizados possam ser substituídos por pinos lisos com roscas apenas nas extremidades, evitando concentração de tensões nas paredes dos bambus, e possível rachadura da barra de bambu.

Para as colunas de feixe, uma grande vantagem desta solução é o fato de que este tipo de coluna não necessita de perfurações das paredes dos bambus para a passagem de parafusos, evitando a concentração de tensões que ocorre nos furos, como se observou na coluna composta. Outro aspecto possível é o enchimento de seções locais com resina poliuretana expansiva, que aumentará a resistência ao esmagamento provocado pelas cintas metálicas não interferindo no peso final da coluna.

Conclui-se também que a opção pelo tipo de coluna, seja ela composta, híbrida ou de feixe dependerá das cargas de utilização e relação custo benefício, além do ponto de vista estéticoarquitetônico que não deixa de ser um aspecto subjetivo, mas que faz parte das escolhas e opções arquitetônicas.

Soluções ecologicamente corretas como estas se apresentam como uma conquista social relativa às alternativas construtivas, pois sendo de fácil fabricação, leves e sistêmicas, favorecem a biodiversidade, a conscientização de seus benefícios socioambientais e condições de adaptabilidade à população em geral. 


\section{Referências}

Chages, A., (1974) Principles of Structural Stability Theory. Department of Civil Engineering, University of Massachusetts; Engleewood Cliffs, New Jersey, USA: Prentice-Hall, Inc.

Moreira, L. E., (1998). Aspectos singulares das treliças de bambu: flambagem e conexões. Tese de Doutorado. Rio de Janeiro: PUC-RJ, Departamento de Engenharia Civil.

Moreira, L. E., Silva, F. J., Rodrigues, F.C., (2011). Design and Mechanical Tests of Bamboo Masts. Anais do $13^{\circ}$ International Conference on Non-Conventional Materials and Technologies (NOCMAT). Key Engineering Materials, V.517, p.238-244, Doi: http://dx.doi. org/10.4028/www.scientific.net/KEM.517.238

Moreira, L. E., Ghavami, K., (2011). The influence of initial imperfections on the buckling of bamboo columns. Guayaquil. Ecuador: Proceedings of the International Workshop on the role of Bamboo in Disaster avoidance.

Rodrigues, F., C. (2009) C. Procedimentos de registro da disciplina e ensaios de Análise Experimental de Tensões. Belo Horizonte, MG: Programa de Pós Graduação em Engenharia de Estruturas da EE-UFMG.

Silva, F. J.; Rodrigues, F. C.; Moreira, L. E., (2014). Buckling of Masts of Bamboos Bundles. Key Engineering Materials. v.634, p.379 - 388, Doi: http://dx.doi.org/10.4028/www.scientific.net/kem.634.379

Silva, F. J.; Rezende, M.A.P.; Santos, W.J.; Carrasco, E.; Mantilla, J.N.R.; Piancastelli, E. M.; Magalhães, A.G., (2017). Sustainable Architecture with Bamboo Columns Technology. Applied Mechanics and Materials. v.864, p.318 - 323. Doi: http://dx.doi.org/10.4028/www. scientific.net/amm.864.31

Tung, S., (2010). Study of Mechanical Properties of Bamboo. Master Dissertation, Tokyo: University of Tokyo. 